\title{
Anabases
}

ANABASES Traditions et réceptions de l'Antiquité

23 | 2016

Varia

\section{Veit ROSENBERGER (éd.), " Die Ideale der Alten ». Antikerezeption um 1800}

\section{Lucien Calvié}

\section{OpenEdition}

Journals

Édition électronique

URL : http://journals.openedition.org/anabases/6172

DOI : $10.4000 /$ anabases. 6172

ISSN : 2256-9421

\section{Éditeur}

E.R.A.S.M.E.

\section{Édition imprimée}

Date de publication : 2 mai 2016

Pagination : 335-337

ISSN : 1774-4296

\section{Référence électronique}

Lucien Calvié, "Veit rosenberger (éd.), " Die Ideale der Alten ». Antikerezeption um 1800 », Anabases [En ligne], 23 | 2016, mis en ligne le 02 mai 2016, consulté le 22 septembre 2020. URL : http:// journals.openedition.org/anabases/6172 ; DOI : https://doi.org/10.4000/anabases.6172

Ce document a été généré automatiquement le 22 septembre 2020.

(c) Anabases 


\title{
Veit ROSENBERGER (éd.), " Die Ideale der Alten ». Antikerezeption um 1800
}

\author{
Lucien Calvié
}

1 Autour de 1800, l'intérêt allemand pour l'Antiquité, inauguré en 1755 par Winckelmann dans ses Réflexions sur l'imitation des ceuvres grecques en peinture et en sculpture, atteint un point culminant. Ce tropisme antique s'alimente d'hypothèses et de découvertes dans plusieurs domaines du savoir, par exemple au sujet des poèmes homériques attribués à plusieurs auteurs ou même à un auteur " collectif ", et non plus au seul Homère, ou encore dans le cadre d'une poussée néoclassique en sculpture et en architecture. Cette montée d'un néoclassicisme est liée, à partir des années 1740 et 1750, à l'ouverture des fouilles spectaculaires de Pompéi, d'Herculanum et de Paestum, dans un royaume de Naples qui est un des pôles des Lumières et de l'absolutisme éclairé en Italie et même en Europe. Le musée archéologique de Naples n'est-il pas, aujourd'hui encore, quantitativement, le plus riche du monde sur l'Antiquité gréco-romaine?

2 Les contributions de ce volume sont organisées autour d'un centre, Weimar, cette principauté ayant été, à ce moment-là, autour de Goethe et de son ami Schiller, recruté comme professeur par la proche université d'Iéna, le foyer central d'un " classicisme allemand " (deutsche Klassik) qui est en fait plutôt un néoclassicisme en littérature. Ce volume réunit dix contributions présentées en 2006, à Gotha, lors d'un colloque sur les " réceptions de l'Antiquité autour de 1800 ".

3 Les trois premières s'intéressent à phénomènes littéraires. V. Riedel présente l'étude peu connue de Goethe (né en 1749) sur Winckelmann et son siècle, publiée en 1805. On y voit les Grecs anciens vus par Winckelmann, mais aussi par Goethe, comme des hommes " totaux ", " complets », voire " unitaires " (" wahrhaft ganze Menschen »). Ce thème de la belle et heureuse " totalité grecque ", corps et âme unis, opposée à la triste coupure chrétienne et moderne entre la matière et l'esprit, ou le corps et l'âme, est prégnant à l'époque dans l'intellectualité allemande, par exemple chez Schiller (né en 1759) et son cadet Hölderlin (né en 1770), l'un et l'autre pourtant étrangement absents de ce recueil, malgré des allusions à Schiller. On rencontre aussi ce thème chez le jeune Hegel (lui aussi né en 1770), lié à Hölderlin, au tournant des années 1790, au 
séminaire (Stift) protestant de Tübingen, dans leur Wurtemberg natal, par une amitié en partie politique, révolutionnaire et même " jacobine ». Mais cet aspect-là - celui de la connexion intellectuelle et politique entre une Antiquité revisitée et l'apport novateur de 1789 - de la ferveur allemande pour l'Antiquité semble assez ignoré dans ce volume.

4 Les deux autres contributions " littéraires » sont celles de Renata Gambino et de F. Daumer. La première s'occupe de la différence, en 1786-1787, entre la réception goethéenne des fouilles de Pompéi et celle du romancier Karl Philipp Moritz - né en 1756 et auteur, en 1785-1790, d'un original roman autobiographique, Anton Reiser -, que Goethe considérait affectueusement comme son " petit frère ", plus fragile que lui et moins favorisé par l'origine sociale. Alors que le plébéien Moritz se satisfait d'imaginer la vie quotidienne dans l'Antiquité à partir d'éléments des fouilles, le patricien Goethe se détourne de cette trivialité et aspire à découvrir l'architecture grecque à Paestum, puis en Sicile. La seconde s'intéresse à la réception de l'Antiquité chez l'écrivain " éclairé » Wieland (né en 1733), qui, dans ses Pensées sur des idéaux des Anciens, contre Winckelmann, affirme en 1777 que la beauté des corps dans la statuaire grecque n'est pas le résultat de l'imitation d'une belle nature, mais l'expression d'un idéal à la recherche d'un modèle.

5 Deux contributions (M. Becker et V. Rosenberger) concernent les arts plastiques (les moulages de métal fondu) et l'architecture (le château de Weimar et sa réfection de 1789 à 1804, après l'incendie de 1774), cependant que celle de R. Sternke est dévolue au discours sur l'archéologie, distingué de l'objet archéologique lui-même, chez Karl August Böttiger, au cours des années 1820 et 1830, dans sa correspondance avec l'archéologue français Désiré Raoul-Rochette. Böttiger avait été un familier du " gratin » intellectuel (Goethe, Wieland, Schiller, Herder) au cours de son séjour à Weimar de 1791 à 1804 .

6 Les aspects historiographiques et philosophiques de la réception allemande de l'Antiquité au cours du premier tiers $\mathrm{du} \mathrm{XIX}^{\mathrm{e}}$ siècle sont évoqués dans deux contributions. Celle de F. Saure s'intéresse à la « lubie »- le mot est de Humboldt luimême - de la "ressemblance » entre Grecs anciens et Allemands modernes chez Humboldt, en particulier à propos de la langue comme " souffle et âme d'une nation ", mais aussi de la constitution d'une conscience nationale autour de 1800, en pleine hégémonie française en Allemagne, à partir de données linguistiques et culturelles. S. Rebenich, lui, s'intéresse au rapport de l'historien Droysen (né en Prusse en 1808) à l'Antiquité. Il note l'influence sur ce dernier de la pensée " nationale » de Humboldt, mais aussi de la philosophie hégélienne de l'histoire, en particulier à propos de l'histoire réelle comme lieu de réalisation de la raison et donc de la liberté, avec la coupure consécutive entre un Orient " despotique » et une Grèce " libre ». Il rappelle aussi le parallèle développé par Droysen, dans son livre de 1833 sur Alexandre, entre les " missions » unificatrices de la Macédoine antique et de la Prusse moderne pour les Grecs anciens comme pour les Allemands modernes, la deuxième édition du livre, celle de 1877, accentuant opportunément ce parallèle.

7 Les deux dernières contributions, celles de Grazia Pulvirenti et de L. Morenz, concernent, pour la première, la réception de l'Égypte dans les milieux cultivés européens, maçonniques en particulier (Mozart dans La flûte enchantée), au XVIII siècle, et, pour la seconde, la campagne d'Égypte de Bonaparte de 1798 à 1801 et sa portée culturelle, en particulier par le biais de la prestigieuse Description de l'Égypte parue à 
Paris de 1809 à 1822, document fondateur de l'égyptologie moderne. C'est dans cette Description que Champollion publie en 1822 son déchiffrage décisif de l'écriture hiéroglyphique.

8 On pourra s'étonner, pour conclure, de l'absence de tout contributeur français dans ce volume pourtant fortement orienté vers une France servant souvent, à l'époque considérée, à la fois de pôle d'attraction et de répulsion : signe de faiblesse de la recherche française, ou bien de l'initiative scientifique du côté allemand ?

\section{AUTEUR}

\section{LUCIEN CALVIÉ}

Université Toulouse-Jean Jaurès (UT2J)

claude.calvie@orange.fr 